\title{
Modified peach stones by ethylenediamine as a new adsorbent for removal of $\mathrm{Cr}(\mathrm{VI})$ from wastewater
}

Guihong Lan, ${ }^{\mathrm{a}, \mathrm{b}}{ }^{*}$, Yingting Zhang ${ }^{\mathrm{a}}$, Yongqiang Liu ${ }^{\mathrm{c}}$, Haiyan Qiu ${ }^{\mathrm{a}, \mathrm{b}}$, Peng Liu ${ }^{\mathrm{d}}$, Junhua Yan ${ }^{\mathrm{e}}$, Tailiang Zhang ${ }^{\mathrm{f}}$

${ }^{a}$ College of Chemistry and Chemical Engineering, Southwest petroleum University, Chengdu,

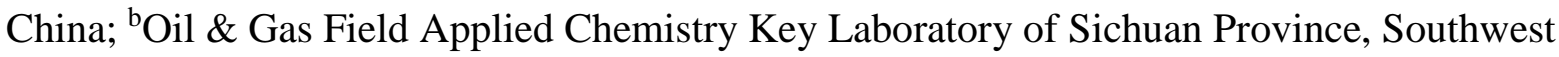
Petroleum University, Chengdu, China; ${ }^{c}$ Faculty of Engineering and Physical sciences, University of Southampton, Southampton, United Kingdom; d Northwest Sichuan Gas Mine,

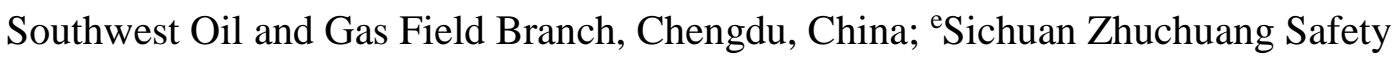

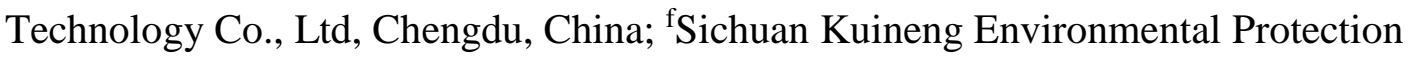
Technology Co., Ltd, Chengdu, China

Abstract: The potential of modified peach stone (PS) for $\mathrm{Cr}$ (VI) removal from wastewater was explored in this work. First of all, the properties of the modified peach stone were characterized by SEM, TGA, FT-IR and elemental analysis . Secondly, the modified peach stone were used to absorb Cr (VI). It was found that $3 \mathrm{~g} / \mathrm{L}$ EPS was good enough for removal of $\mathrm{Cr}(\mathrm{VI})$ in feed solution with the maximum adsorption capacity for $\mathrm{Cr}$ (VI) of $24.68 \mathrm{mg} / \mathrm{g}$. Either pseudo-second-order model or Langmuir adsorption model was well fitted with the adsorption data. In addition, EPS was found to be able to be reused for a number of cycles for a sustainable operation. This study demonstrates that EPS as a modified natural agriculture waste has great potential to remove $\mathrm{Cr}(\mathrm{VI})$ from wastewater.

Keywords: Peach stone; modified; adsorption; Cr (VI); amino; wastewater 


\section{Introduction}

The rapid development of industries and the wide application of different types of technologies bring more and more pollution into our lives, leading to severe harm to the environment and public health. Industrial production such as paper, chrome ore, dyestuff, pigment manufacturing, electroplating, leather tanning, textile industry, refractories and wood corrosion protection $^{[1-2]}$, is the main source of chromium pollution. Heavy metals such as chromium are usually toxic and non-biodegradable. Furthermore, they are very easy to amass in organisms and then to cause harmful side effects on the whole ecosystem through the food chain. Chromium is one of the common heavy metals which exists in the environment in the forms of $\mathrm{Cr}$ (III) and $\mathrm{Cr}$ (VI) with high toxicity and carcinogenicity even at low concentration ${ }^{[4]}$. $\mathrm{Cr}(\mathrm{VI})$ is 500 times more toxic than $\mathrm{Cr}$ (III) ${ }^{[5]}$. The presence of $\mathrm{Cr}$ (VI) may cause allergy, dermatitis, neurotic disorder and even cancer ${ }^{[6]}$. The maxim limits for $\mathrm{Cr}$ (VI) in inland and potable water are 0.1 and $0.05 \mathrm{mg} / \mathrm{L}^{[7]}$, respectively. Therefore, it is essential to remove it before being discharged from the industries into the environment.

To effectively remove heavy metals from wastewater, a number of methods have been employed which include precipitation, flocculation, ion exchange and adsorption ${ }^{[8,9]}$. Among these methods, adsorption is being widely used due to low cost and high efficiency. In recent years, activated carbon as an effective adsorbent has been widely utilized for wastewater treatment. The application of activated carbon in the practice, however, is limited because of high cost and difficulty for regeneration. To effectively and economically remove heavy metals from wastewater, more and more research has been conducted on developing adsorbents from agriculture wastes due to their abundance, easy availability and low cost or even no $\operatorname{cost}^{[9-10]}$, The agricultural wastes which have been studied for the adsorption of heavy metals from effluents include soybean meal ${ }^{[11]}$, rice husk ${ }^{[12]}$, wheat bran ${ }^{[13]}$ and 
walnut shells ${ }^{[14]}$. However, the adsorption capacity of untreated agricultural materials is not high. A large number of studies have focused on the chemical modifications to enhance their heavy metal removal efficiency ${ }^{[15-17]}$.

Peach stone (PS) as an kind of agricultural waste from peach (Prunus persica) is inevitable to have safe disposal issue and even environmental problem. Like other agricultural residues and by-products, peach stone is mainly composed of cellulose, hemicellulose, and lignin. Peach stone thus can be used as adsorbent to remove $\mathrm{Cr}$ (VI) from wastewater at low cost by transformingwaste to highly efficient adsorbent ${ }^{[18]}$. Although the adsorption capacity of virgin peach stone may not be high enough, different modification methods can be utilized to improve its adsorption capacity.

This study thus aims to develop a new kind of adsorbent with high $\mathrm{Cr}(\mathrm{VI})$ adsorption capacity by modifying peach stone with ethylenediamine. It is expected that such kind of adsorbent could be able to effficiently adsorb $\mathrm{Cr}$ (VI) from wastewater. The raw and modified materials were characterized by various approaches such as Fourier transformed infrared spectroscopy (FTIR), scanning electron microscopy (SEM), thermogravimetric analysis (TGA) and elemental analyzer to understand their adsorption mechanism. The batch adsorption experiment was performed with variations of initial concentration of $\mathrm{Cr}$ (VI), contact time, $\mathrm{pH}$ and dosage. Moreover, we also evaluate equilibrium and kinetics aspects of adsorption process as well as regeneration to exploit the future commercial application.

\section{Materials and methods}

\subsection{Peach stone and Chemicals}

Peach stones were obtained from Longquan district, Chengdu, China. Sodium hydroxide, ethylenediamine (EDA), epichlorohydrin, potassium dichromate and sodium carbonate were 
purchased from Kelong chemical reagent factory (Chengdu, China), which were of analytical grade. Deionized water was used in all experiments, with each experiment triplicated.

\subsection{Pretreatment of peach stones}

Peach stones were washed with deionized water to remove soil, dust and other impurities, followed by drying in an oven for $24 \mathrm{hr}$ at $90^{\circ} \mathrm{C}$. Before being used, dried peach stones were ground in a ball mill and sieved to obtain 50-60 mesh fractions (labeled as PS), and stored in plastic bags for the subsequent experiments ${ }^{[19]}$.

2.3 EDA modification of peach stones 20 grams of the sieved peach stone was immersed in $0.1 \mathrm{M} \mathrm{NaOH}$ solution with stirring for 1 hour at room temperature for (what? Better to write the purpose of alkaline immersion for $1 \mathrm{hr}$ ) .Deionized water was then used to wash peach stone to neutral, followed by drying overnight in the oven at $50^{\circ} \mathrm{C}$ for the subsequent chemical modificaiton. ${ }^{[19]} 10 \mathrm{~g}$ dried sample was mixed with $80 \mathrm{ml}$ of $5 \% \mathrm{NaOH}$ and $30 \mathrm{ml}$ of epichlorohydrin in the round bottom flask containing magnetic stir bar for $5 \mathrm{hr}$ under $50^{\circ} \mathrm{C}$

[20]. The reaction products were filtered and washed by DI water until the $\mathrm{pH}$ reached 7 . Then the solid was dried overnight at $50^{\circ} \mathrm{C}$. After drying, $2 \mathrm{~g}$ of the products was mixed with $0.5 \mathrm{~g}$ $\mathrm{Na}_{2} \mathrm{CO}_{3}$ and $50 \mathrm{ml}$ of EDA in a round-bottomed flask with a magnetic stirring bar for hours and washed with deionized till the $\mathrm{pH}$ almost approaches near 7. Finally, the products were dried in the oven for $24 \mathrm{hr}$ at $50^{\circ} \mathrm{C}$, and labeled as EPS.

\subsection{Batch adsorption studies by EDA modified peach stones}

All Cr (VI) adsorption experiments were carried out in a shaking table at $250 \mathrm{r} / \mathrm{min}$ and $30^{\circ} \mathrm{C}$. Cr (VI) stock solution at $50 \mathrm{mg} / \mathrm{L}$ was prepared by dissolving potassium salts of dichromate into deionized water. The $\mathrm{pH}$ values of the solutions were adjusted with ?? $\mathrm{M}$ of 
$\mathrm{NaOH}$ or ?? $\mathrm{M}$ of $\mathrm{HCl}$ solution. $0.15 \mathrm{~g}$ absorbents were added into conical flask for all the experiments except the study on the adsorption dose. The adsorption duration from 10 to 300 min was also investigated to figure out the equilibrium time. The adsorption isotherm experiments were studied with different initial $\mathrm{Cr}$ (VI) concentrations ranging from 24 to 400mg/L. The initial Cr (VI) concentration, $\mathrm{pH}$ and contact time were 50mg/L, 2.5 and 180 min, respectively, except the special note.

The concentration of $\mathrm{Cr}$ (VI) in the solution was measured by flame atomic absorption spectrophotometry (FAAS, AA-7020, Beijing, China). The adsorption capacity $\left(q_{e} \mathrm{mg} / \mathrm{g}\right)$ and removal rate $(w \%)$ were calculated according to the following equations:

$$
\begin{gathered}
q_{e}=\frac{\left(C_{0}-C_{e}\right) V}{m} \\
\mathrm{w}=\frac{C_{0}-C_{e}}{C_{0}} \times 100 \%
\end{gathered}
$$

Where $q_{e}$ and $w$ were the uptake amount $(\mathrm{mg} / \mathrm{g})$ and the removal rate $(\%)$ at equilibrium, respectively. $C_{0}$ and $C e$ were the initial and equilibrium concentration of $\mathrm{Cr}$ (VI) in solution; $V$ was the volume of solution and $\mathrm{m}$ was the mass of absorbent.

\subsection{Characterization of absorbents}

CHN Elemental Analyzer (Var10EL-III, Germany) was used to obtain the C, H and N contents of the materials before and after modification. The surface of the nascent as well as the spent absorbents were characterized by using FTIR spectrometer (WQF520, China). The surface morphology of samples were observed by using a scanning electron microscopy (SEM, JSM-7500F) at $10.0 \mathrm{kV}$. The changes in physical and chemical properties of PS and EPS with temperature were monitored by using the thermal gravity analysis (TGA, NETZSCH STA 449F3) under air atmosphere scanned from 40 to $650^{\circ} \mathrm{C}$. 


\section{Results and discussion}

\subsection{Effects of key conditions on modification of peach stone}

To explore the effects of EDA concentration, reaction time and temperature on modification, batch modification experiments were carried out at variable EDA concentrations from 0.5 to $2.25 \mathrm{M}$, reaction time from 2-6 h, reaction temperature from 40 to $100^{\circ} \mathrm{C}$. The best modification conditions were confirmed by measuring increased $\mathrm{N}$ content. The modification mechanism was illustrated in Fig.1.

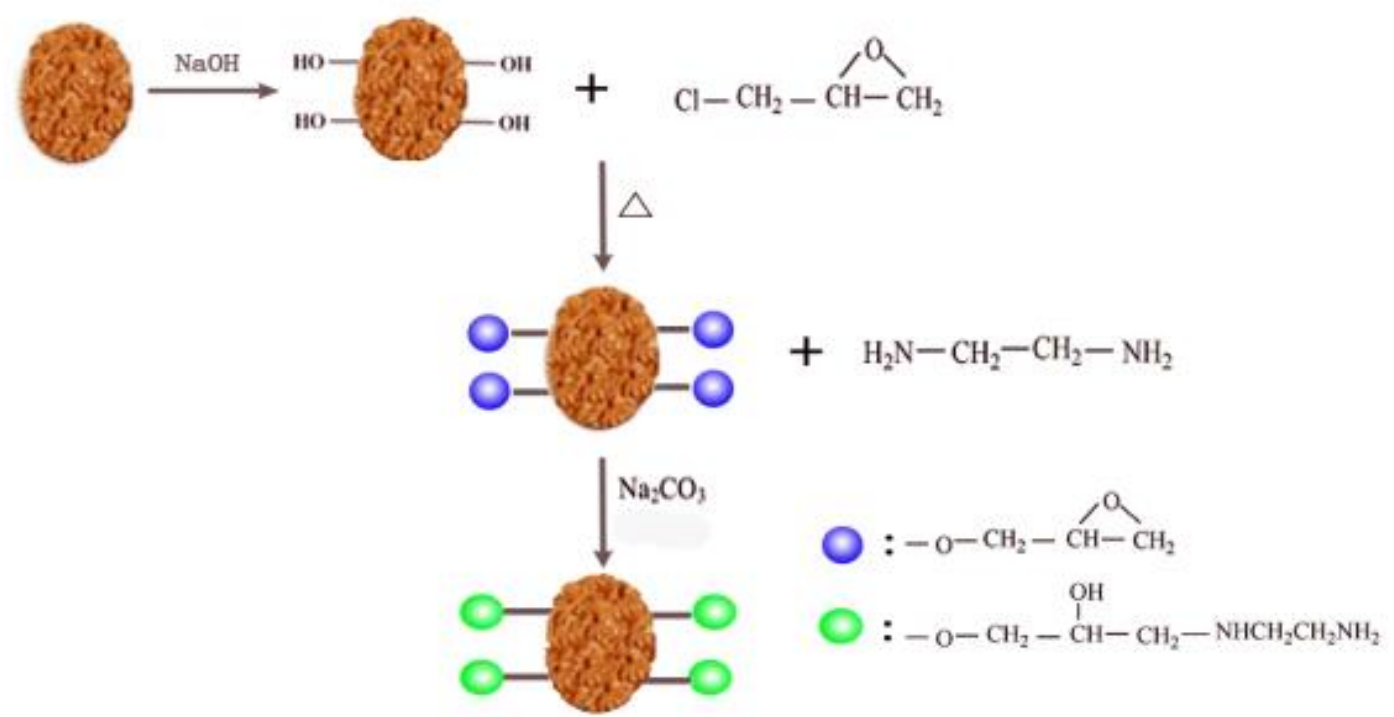

Fig.1 Reactions involved during the ethylenediamine modification of peach stones

Fig.2 shows the effects of modification conditions on $\mathrm{N}$ content of modified peach stons. It was found that the $\mathrm{N}$ content of the modified peach stones increased sharply with the increase in EDA concentration from 0 to $0.75 \mathrm{M}$ whileplateaued with $0.75-1.25 \mathrm{M}$ EDA concentration. When EDA concentration further increased to $2.25 \mathrm{M}, \mathrm{N}$ content decreased slightly. The maximum $\mathrm{N}$ content was achieved at EDA concentration of $1.25 \mathrm{M}$. N\% profiles of EPS with reaction time and temperature are similar, and the optimal reaction time and temperature for the maximum $\mathrm{N} \%$ were found at $4 \mathrm{hr}$ and $60^{\circ} \mathrm{C}$, respectively. Therefore, 
1.25 M EDA, $4 \mathrm{hr}$ reaction time and $60^{\circ} \mathrm{C}$ were chosen as the optimum conditions for the modification of peach stones as absorbents for the subsequent batch adsorption experiments. 

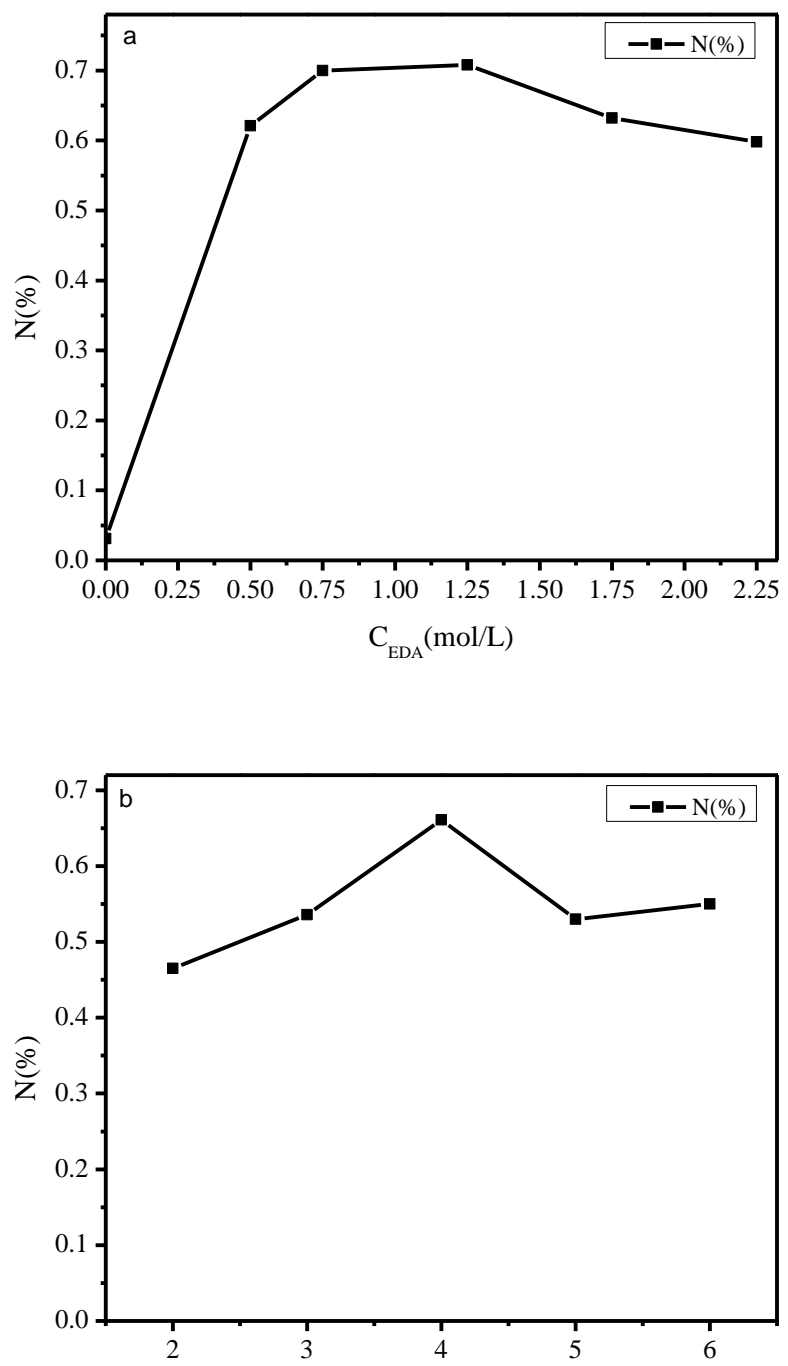

$\mathrm{t}(\mathrm{h})$

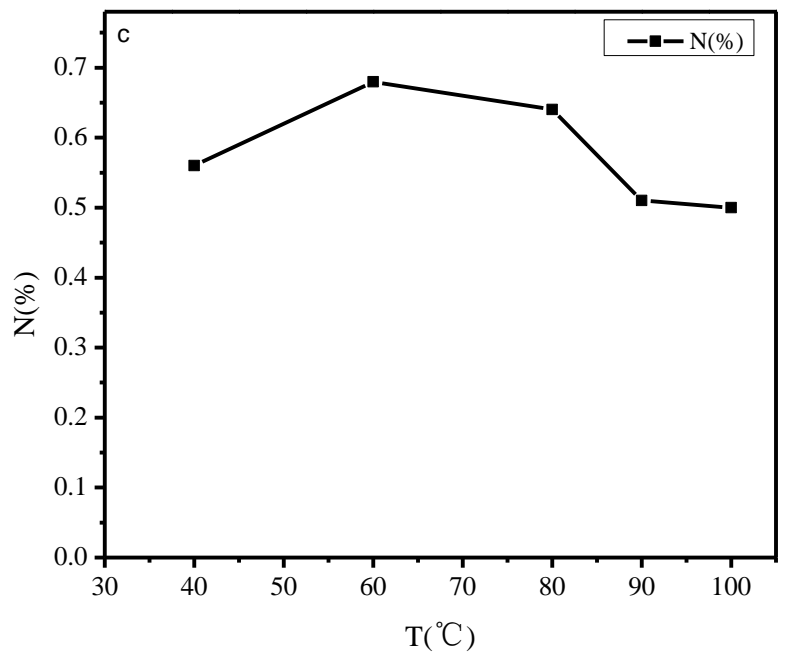


Fig.2 Effects of the concentration of EDA (a), reaction time (b) and temperature (c) on $\mathrm{N}$ content of EDA modified peach stones

\subsection{Characterization of adsorbents}

\subsubsection{FTIR analysis}

FTIR spectra analysis is used to examine the functional groups of the absorbents. The FTIR spectra of PS, epichlorohydrin-PS, EPS, and Cr (VI) absorbed EPS were shown in Fig.3. It can be seen that for PS, there was a strong and broad peak at around $3,441 \mathrm{~cm}^{-1}$ which was attributed to hydroxyl groups. The peak at $2,907 \mathrm{~cm}^{-1}$ was ascribed to the $\mathrm{CH}$ stretching band and the characteristic vibration peak at $1,745 \mathrm{~cm}^{-1}$ was assigned to the carboxyl groups in hemicellulose. The adsorption peak at $1,254 \mathrm{~cm}^{-1}$ was due to the syringyl ring and $\mathrm{CO}$ stretching in lignin and hemicellulose and the band around $1,039 \mathrm{~cm}^{-1}$ was the characteristic of the $\mathrm{COC}$ and $\mathrm{OH}$ groups of primary hydroxyl stretching in cellulose and hemicellulose [2, 21]. Compared with the spectrum of PS, it was found that for epichlorohydrin-PS, the characteristic absorption peak at $1,039 \mathrm{~cm}^{-1}$ shifted to $1,029 \mathrm{~cm}^{-1}$, and the peak became sharper probably due to the etherification of $-\mathrm{OH}$ on cellulose with epichlorohydrin. In addition, the phenomena that some peaks of PS at $1,195 \mathrm{~cm}^{-1}$ to 1,742 $\mathrm{cm}^{-1}$ disappeared, the peak at $1,639 \mathrm{~cm}^{-1}$ widened, the intensity of peaks at $1,639 \mathrm{~cm}^{-1}$ and $3,434 \mathrm{~cm}^{-1}$ increased, confirmed a successful etherification of the functional groups on PS surface with epichlorohydrin by ${ }^{[22]}$. Meanwhile, the shift of peak position and the change of peak intensity at $1,038,1,639$ and $3,434 \mathrm{~cm}^{-1}$ further confirmed that the etherification process was mainly achieved between epichlorohydrin and $-\mathrm{OH}$. After the further modification of epichlorohydrin-PS by EDA, the peak at $1,029 \mathrm{~cm}^{-1}$ became narrower with the peak intensity enhanced. The peaks at $1,639 \mathrm{~cm}^{-1}$ and $3,434 \mathrm{~cm}^{-1}$ obviously broadened which were attributed to the introduction of $-\mathrm{NH}_{2}$. 
After the adsorption of $\mathrm{Cr}$ (VI) by EPS, the characteristic peak at $1,029 \mathrm{~cm}^{-1}$ broadened further in accompany with the reduced intensity. The peak intensity ${ }^{[2]}$ at 1639 and $3,434 \mathrm{~cm}^{-1}$ decreased too. It is probably due to the contribution of $-\mathrm{NH}_{2},-\mathrm{OH},-\mathrm{COOH}$ and some other groups to the adsorption of $\mathrm{Cr}(\mathrm{VI})$. It thus can be concluded that the modification of peach stone by EDA by introducing a lot of $-\mathrm{NH}_{2}$ to change the function groups on PS surface is successful as expected to enhance the adsorption capacity to $\mathrm{Cr}$ (VI).

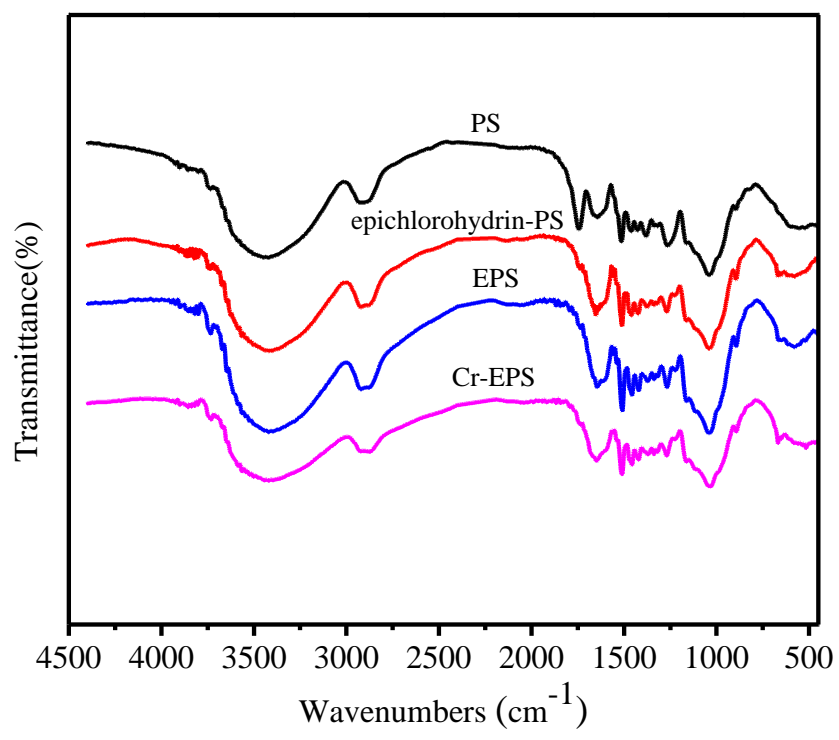

Fig.3 FTIR spectra of PS, epichlorohydrin-PS, EPS, Cr (VI)-EPS

\subsubsection{Elemental analysis of PS and EPS}

Peach stone was mainly composed of cellulose, hemicelluloses and lignin, which shows the easiness for chemical modification. Based on elemental analysis as shown in Table 1, EPS has high contents of $\mathrm{C}$ and $\mathrm{O}$, but low $\mathrm{N}$ content. After modification by EDA, both contents of $\mathrm{H}$ and $\mathrm{N}$ increased while $\mathrm{C}$ content decreased, indicating the successful introduction of $-\mathrm{NH}_{2}$ by substitution reaction

Table 1 The elemental analysis results of PS and EPS 


\begin{tabular}{ccccc}
\hline & $\mathrm{C}(\%)$ & $\mathrm{O}(\%)$ & $\mathrm{H}(\%)$ & $\mathrm{N}(\%)$ \\
\hline PS & 48.13 & 45.64 & 6.201 & 0.031 \\
EPS & 47.59 & 45.41 & 6.342 & 0.661 \\
\hline
\end{tabular}

PS: peach stone; EPS: peach stone modified by ethylenediamine

\subsubsection{Themogravimetric analysis of PS and EPS}

TG analysis was conducted to understand the thermal stability of PS and EPS. The TG curves of PS and EPS were showed in Fig. 4. It can be seen that there are three stages of mass loss, which could correspond to water loss, pyrolysis and combustion of organic matters in PS, respectively More weight loss (about 5\%) was observed in EPS compared to PS at temperature about $151^{\circ} \mathrm{C}$, which was due to the loss of free water. When temperature went up further to $370^{\circ} \mathrm{C}$, both PS and EPS experienced substantial mass loss (the weight loss of both PS and EPS was approximately 45\%), which was mainly attributed to the thermal decomposition of cellulose, hemicellulose and lignin ${ }^{[23,24]}$. When temperature continued to rise PS mass loss mainly occurs in the temperature range of 368 to $514^{\circ} \mathrm{C}$, which was mainly attributed to the combustion of fixed carbon of lignin and cellulose in $\mathrm{PS}^{[19]}$. Above $514^{\circ} \mathrm{C}$, , the mass of PS did not changes any more, indicating that only ash was left. For EPS, the mass loss at the third stage lasted from 368 to $600^{\circ} \mathrm{C}$, which is very different from PS. This suggests that the modification of PS changes its thermal characteristics. The ash content for both PS and EPS are equivalent, which further indicates that the change of thermal characteristics is mainly caused by chemical modification. 


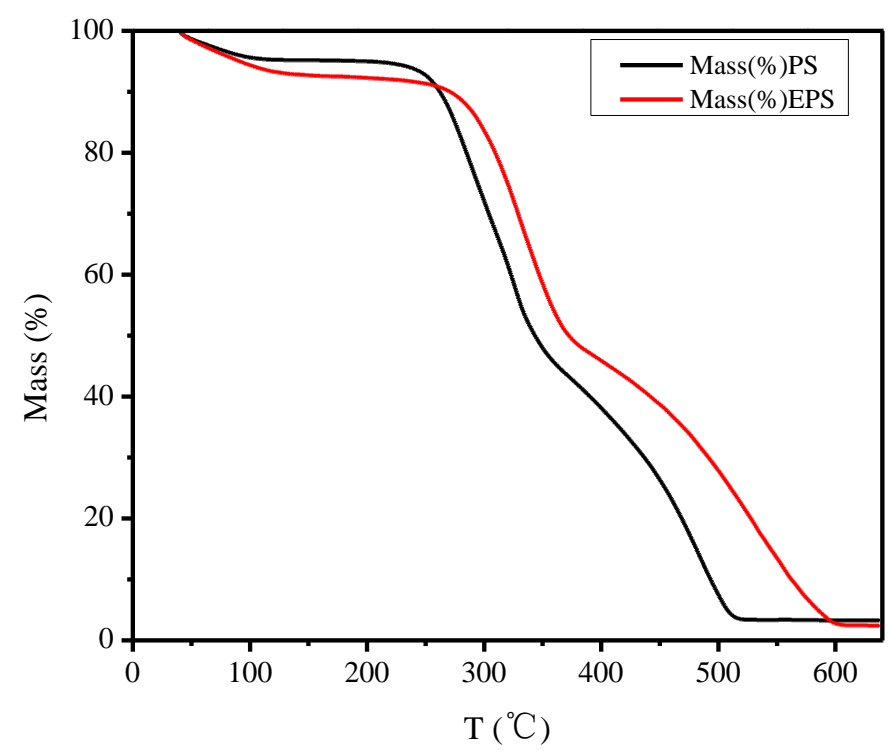

Fig.4 TG curves of PS and EPS

\subsubsection{SEM analysis of PS and EPS}

The scanning electron micrographs of PS and EPS were shown in Fig. 5. The micrographs showed a large amount of impurities on the surface of PS. In addition, a large number of pores on the surface of PS were blocked (Fig.5 (a)). However, after the PS was modified by EDA as shown in Fig.5 (b), the surface became cleaner and the number of holes was significantly improved. This is mainly because that the impurities and pigments on PS surface were removed during the modification process. The more pores in EPS indicates the higher specific surface area, which is favorable to adsorption of $\mathrm{Cr}$ (VI). 

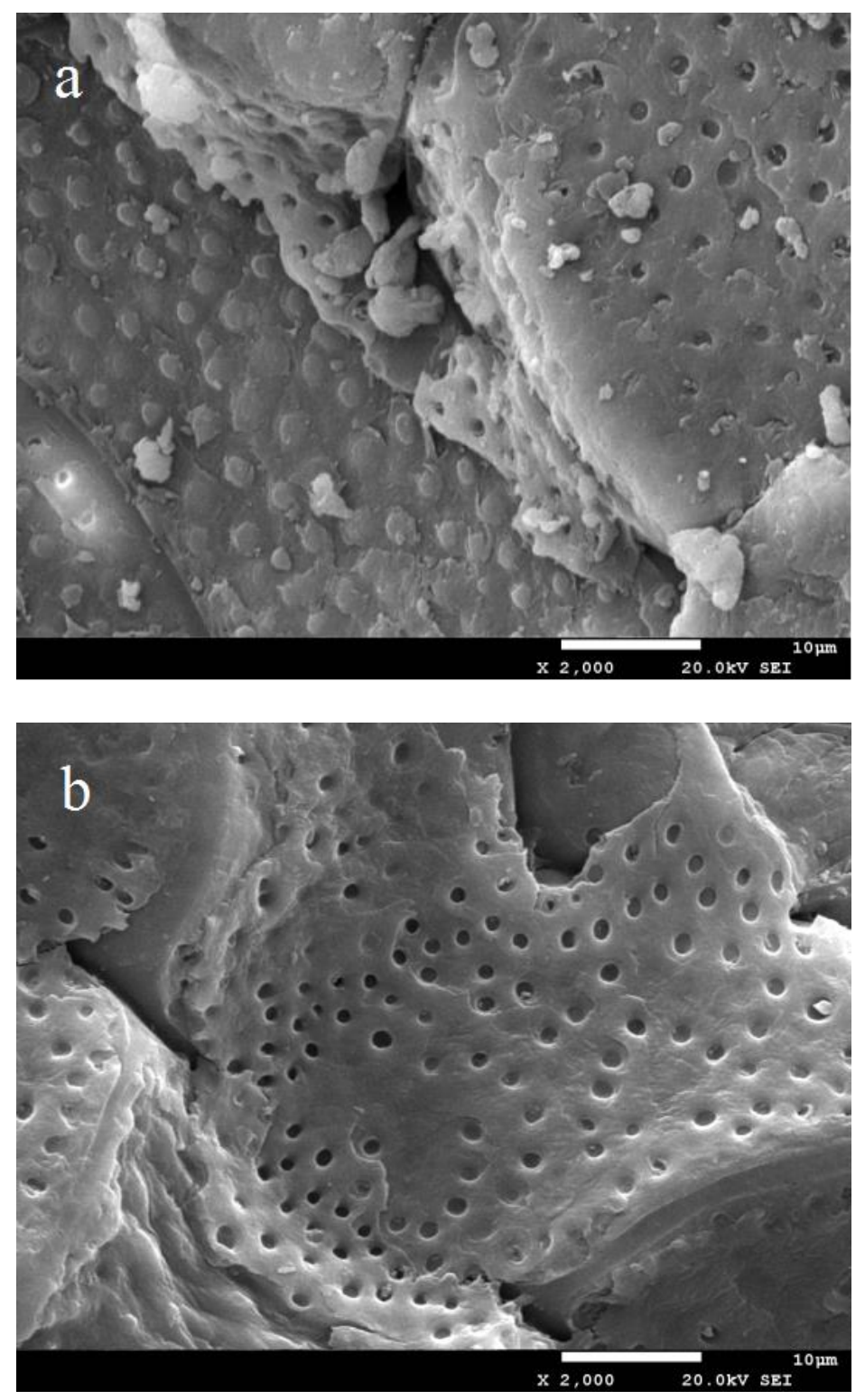

Fig.5 SEM micrographs of PS (a), and EPS (b)

\subsection{Comparison of $\mathrm{Cr}(\mathrm{VI})$ adsorption by PS and EPS}

In order to compare the adsorption of $\mathrm{Cr}(\mathrm{VI})$ by peach stones before and after modification, $0.15 \mathrm{~g}$ of PS and EPS were used to adsorb $\mathrm{Cr}(\mathrm{VI})$ from $50 \mathrm{~mL}$ solution with $\mathrm{Cr}$ (VI) concentration of $50 \mathrm{mg} / \mathrm{L} \mathrm{Cr}(\mathrm{VI})$ at $\mathrm{pH} 2.5$ and temperature of $30^{\circ} \mathrm{C}$. It can be seen from Fig.6. that over the time, the adsorption of Cr(VI) by EPS increased exponentially at first and then increased slowly and gradually reached a steady state. For PS, no obvious adsorption in the first three hours was observed although there was a slight adsorption from 
200 to 300 minutes and then plateaued. The maximum adsorption capacity of EPS to $\mathrm{Cr}(\mathrm{VI})$ is $13.90 \mathrm{mg} / \mathrm{g}$ while it is only $4.14 \mathrm{mg} / \mathrm{g}$ for PS, indicating that the $\mathrm{Cr}(\mathrm{VI})$ adsorption capacity after the modification by ethylenediamine is significantly improved.

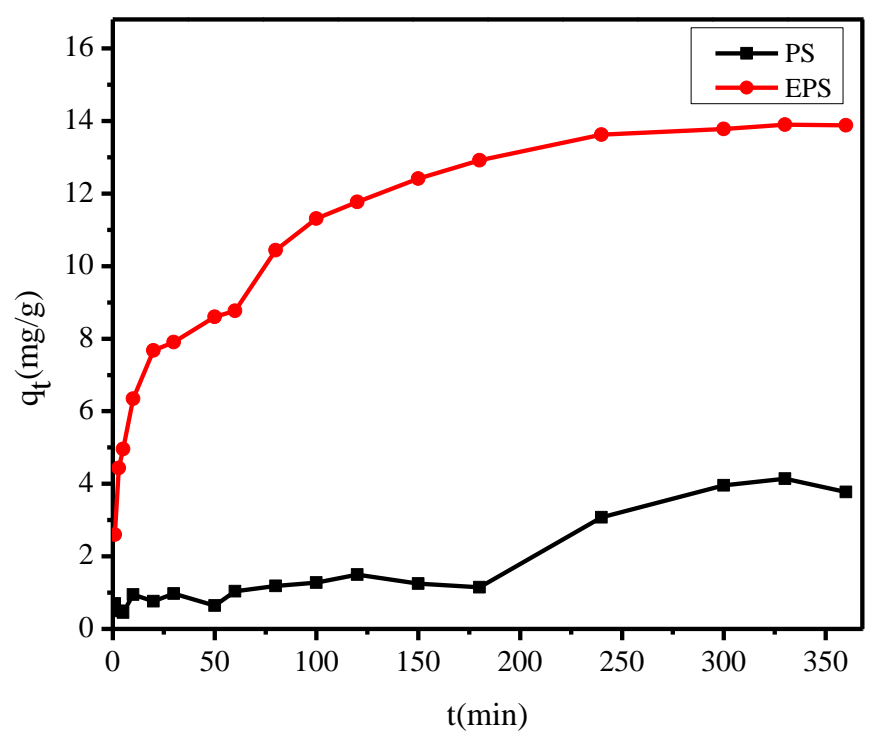

Fig.6 Comparison of Cr (VI) adsorption by PS and EPS

\subsection{Effects of pH on Cr (VI) adsorption by EPS}

The $\mathrm{pH}$ of the solution was an important parameter to the $\mathrm{Cr}$ (VI) removal because of the surface charge and ionic competition. The effect of initial $\mathrm{pH}$ varying from 2.0 to 9.0 for $\mathrm{Cr}$ (VI) removal was shown in Fig.7. It was observed that the adsorption capacity of Cr (VI) decreased dramatically with the increase in wastewater $\mathrm{pH}$ when $\mathrm{pH}$ is above 2.5. The maximun $\mathrm{Cr}(\mathrm{VI})$ adsorption capacity was achieved at $\mathrm{pH} 2.5$. At lower $\mathrm{pH}$, positive charges were the dominant species on the surface of absorbent due to the protonation, thus the electrostatic attraction between the positive charges on the adsorbent surface and the negatively charged $\mathrm{HCrO}_{4}{ }^{-}, \mathrm{Cr}_{2} \mathrm{O}_{2}{ }^{7-}, \mathrm{CrO}_{2}{ }^{4-}$ could give rise to the increase in the adsorption capacity ${ }^{[25]}$. Meanwhile, the presence of $-\mathrm{NH}_{3}{ }^{+}$introduced by the modification also contributes to $\mathrm{Cr}(\mathrm{VI})$ adsorption by electrostatic attraction. The increase in $\mathrm{pH}$ resulted in the 
decreased the adsorption of $\mathrm{Cr}$ (VI) due to the strong competition between hydroxyl ions and $\mathrm{HCrO}_{4}^{-}, \mathrm{Cr}_{2} \mathrm{O}_{2}{ }^{7-}$, and $\mathrm{CrO}_{2}{ }^{4-}$. With $\mathrm{pH}$ change in the wastewater, the forms of $\mathrm{Cr}(\mathrm{VI})$ in the solution was diversified. Thus, the competition existed not only between $\mathrm{Cr}$ (VI) ions in each form, but also between $\mathrm{Cr}(\mathrm{VI})$ ions and $\mathrm{OH}^{-} .2 .5$ was thus chosen as the optimal $\mathrm{pH}$ to carry out the subsequent investigation.

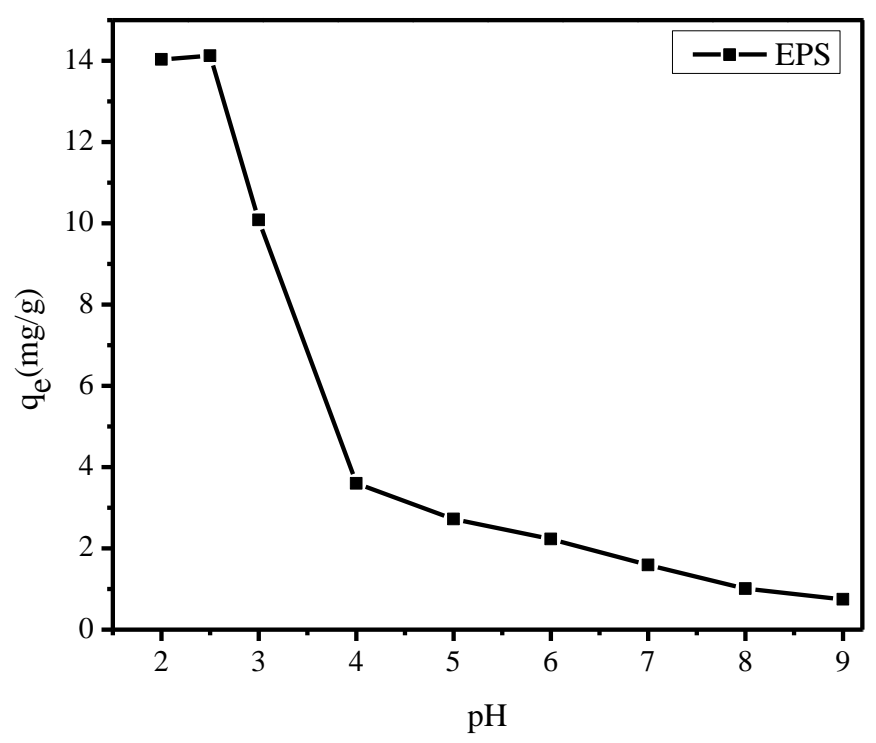

Fig.7 Effect of solution pH on Cr (VI) adsorption onto EPS

\subsection{Effects of adsorbent dosage}

The effects of adsorbent dose on the removal of $\mathrm{Cr}$ (VI) were studied at temperature of $30^{\circ} \mathrm{C}$ and $\mathrm{pH}$ at 2.5 in the medium solution where the initial concentration of $\mathrm{Cr}(\mathrm{VI})$ in the solution was $50 \mathrm{mg} / \mathrm{L}$. In this study, the adsorption of Cr (VI) by EPS was examined with an adsorbent dosage ranging from $1 \mathrm{~g} / \mathrm{L}$ to $6 \mathrm{~g} / \mathrm{L}$ (Fig. 8). It shows that the specific adsorption capacity decreased with the increase in adsorption dosage. The maximum $\mathrm{Cr}$ (VI) removal efficiency was achieved with $3 \mathrm{~g} / \mathrm{L}$ of EPS dosage and a further increase in adsorbent dose showed no quantitative effect on Cr (VI) removal efficiency. It may be due to more active sites and big surface area offered by the adsorbent. So $3 \mathrm{~g} / \mathrm{L}$ was chosen as the optimum dose to remove $\mathrm{Cr}$ (VI) from the solution. 


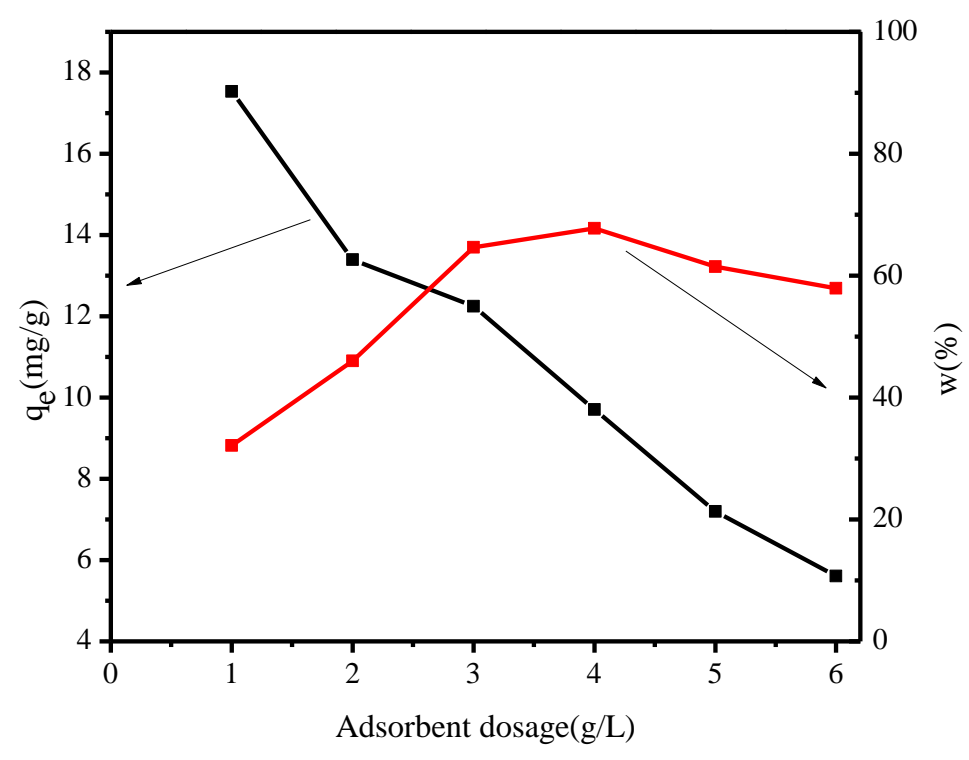

Fig.8 Effect of adsorbent dosage on Cr (VI) onto EPS

\subsection{Variation of contact time and adsorption kinetics}

Contact time was an important parameter to determine the adsorption efficiency. The variation of contact time indicated that the removal efficiency of $\mathrm{Cr}$ (VI) increased with the prolongation of adsorption. As shown in Fig.9, the initial adsorption was very rapid. After $180 \mathrm{~min}$, the adsorption equilibrium was nearly established although there is still a certain level of increase in the adsorption capacity. The equilibrium indicates that initially all available active sites on adsorbents are saturated now with $\mathrm{HCrO}_{4}{ }^{-}, \mathrm{Cr}_{2} \mathrm{O}_{2}{ }^{7-}$, and $\mathrm{CrO}_{2}{ }^{4-}$, Therefore, 180 min was selected as the adsorption time for further experiments. 


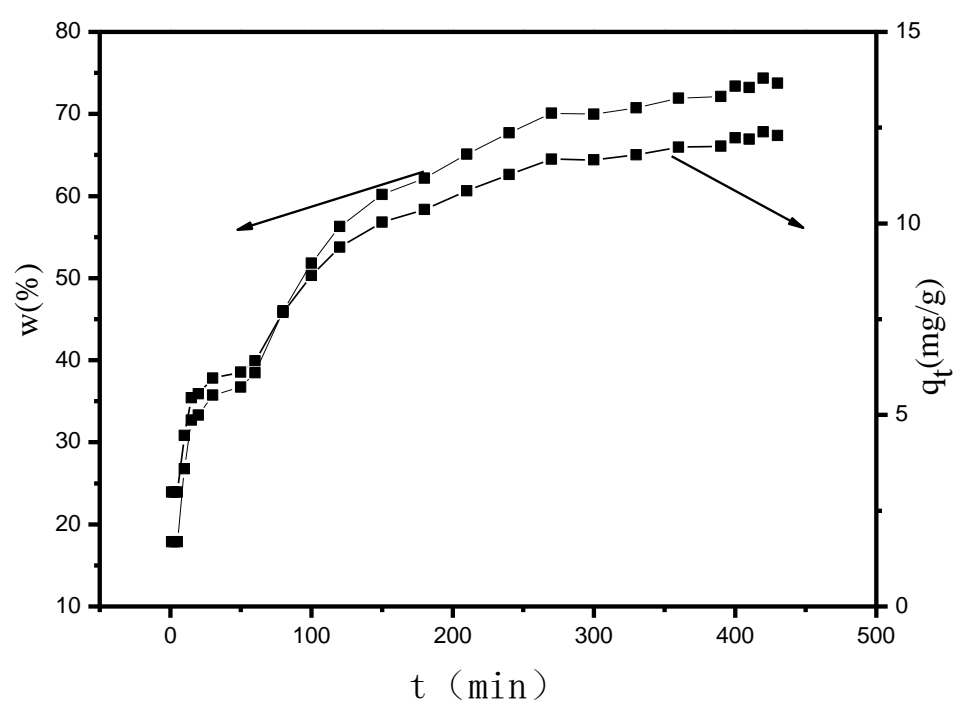

Fig.9 Effect of contact time on Cr (VI) adsorption by EPS

To understand the adsorption process further, the pseudo-second-order and intra-particle diffusion models, respectively, were applied to simulate the adsorption data. The pseudosecond-order rate model ${ }^{[26]}$ is described in the following equation:

$$
\frac{\mathrm{t}}{q_{t}}=\frac{1}{k q_{e}{ }^{2}}+\frac{t}{q_{e}}
$$

The intraparticle diffusion model ${ }^{[27]}$ can be used to analyze the kinetic data to provide insights to the diffusion mechanism, which is expresses as below:

$$
q_{t}=k_{p} t^{0.5}+C
$$

Where $q_{e}(\mathrm{mg} / \mathrm{g})$ and $q_{t}(\mathrm{mg} / \mathrm{g})$ denote the adsorption uptake of $\mathrm{Cr}$ (VI) by EPS at equilibrium and at time $t$, respectively. $K\left(\mathrm{~g} \cdot \mathrm{mg}^{-1} \cdot \mathrm{min}^{-1}\right)$ is the pseudo-second-order rate constant calculated from the plots of $t / q_{t}$ against $t$, and $k_{p}\left(\mathrm{mg} \cdot \mathrm{h}^{0.5} \cdot \mathrm{g}^{-1}\right)$ is the intra-particle diffusion rate constant gained from the slope of straight-line portions of the plots of $q_{t}$ against $t^{0.5}$, and $C$ is the constant obtained from the intercept of the plots. 
Adsorption kinetic was studied at temperature: $30^{\circ} \mathrm{C}$; initial $\mathrm{Cr}$ (VI) concentration: 50mg/L; adsorbent dose: $3 \mathrm{~g} / \mathrm{L}$ and $\mathrm{pH}: 2.5$. All values of kinetic parameters were shown in Table 2.

Table 2 Kinetic parameters for Cr (VI) adsorption by EPS

\begin{tabular}{lcccccc}
\hline & \multicolumn{2}{c}{ Pseudo-second-order kinetic model } & \multicolumn{5}{l}{ Intra-particle diffusion kinetic model } \\
\cline { 2 - 7 } Heavy & $k_{2}(\mathrm{~g} /(\mathrm{mg} \cdot \mathrm{min}))$ & $q_{e}(\mathrm{mg} / \mathrm{g})$ & $R^{2}$ & $k_{y} \mathrm{mg} /\left(\mathrm{min}^{0.5} \cdot \mathrm{g}\right)$ & $\mathrm{C}$ & $R^{2}$ \\
metals & & & & & & \\
\hline $\mathrm{Cr}(\mathrm{VI})$ & 0.004724 & 14.55 & 0.9930 & 0.7240 & 3.463 & 0.9557 \\
\hline
\end{tabular}

As shown in Fig. 10a, Cr (VI) adsorption fits pseudo-second-order kinetics very well with a correlation coefficient $\left(\mathrm{R}^{2}\right)$ of 0.993 . The fitted $q_{e}$ value was consistent with the experimental data. This indicated that the adsorption process can be described by chemisorption. On the other hand, it can be seen from Fig. 10b with intraparticle diffusion model that there were two different linear curves at the initial adsorption stage, indicating that the adsorption process was controlled by more than one process at the initial stage. The good liner relationship with with a rapid adsorption process may be the external surface adsorption, and the intra-particle diffusion step. the liner plots did not pass the origin, indicating that intra-particle diffusion was not the rate controlling step. 

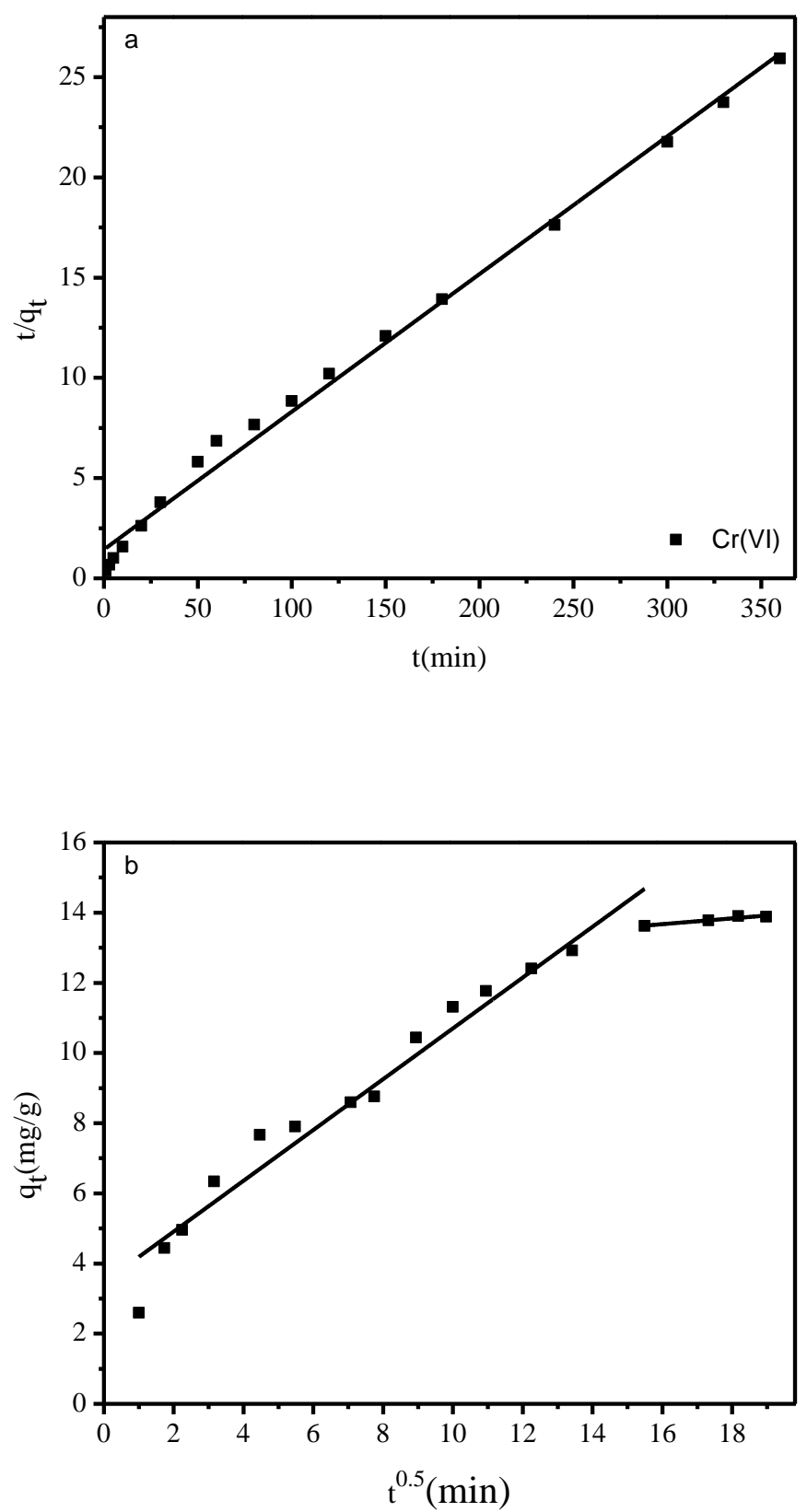

Fig.10 The pseudo-second-order kinetic model (a) and intra-particle diffusion plots (b) on $\mathrm{Cr}$ (VI) adsorption by EPS.

\subsection{Effect of $\mathrm{Cr}$ (VI) concentration and adsorption isotherm}

The effect of initial $\mathrm{Cr}$ (VI) concentration on adsorption was studied with a concentration ranging from 25 to $400 \mathrm{mg} / \mathrm{L}$ and contact time of $180 \mathrm{~min}$, adsorbent dose of $3 \mathrm{~g} / \mathrm{L}$ and $\mathrm{pH}$ at 2.5. an increasing trend of adsorption of $\mathrm{Cr}(\mathrm{VI})$ with the increase in the initial 
Cr (VI) concentration was observed(Fig. 11). This was mainly attributed to the fact that as the initial concentration increased, the $\mathrm{Cr}$ (VI) concentration difference between the adsorbent surface at time of $0 \mathrm{~min}$ and the solution gradually increased, leading to higher concentration difference as the driving force for the adsorption. With the further increase of $\mathrm{Cr}$ (VI) concentration, the active sites are saturated, thus the adsorption would gradually reaches saturation, resulting in unchanged $\mathrm{Cr}(\mathrm{VI})$ adsorption capacity.

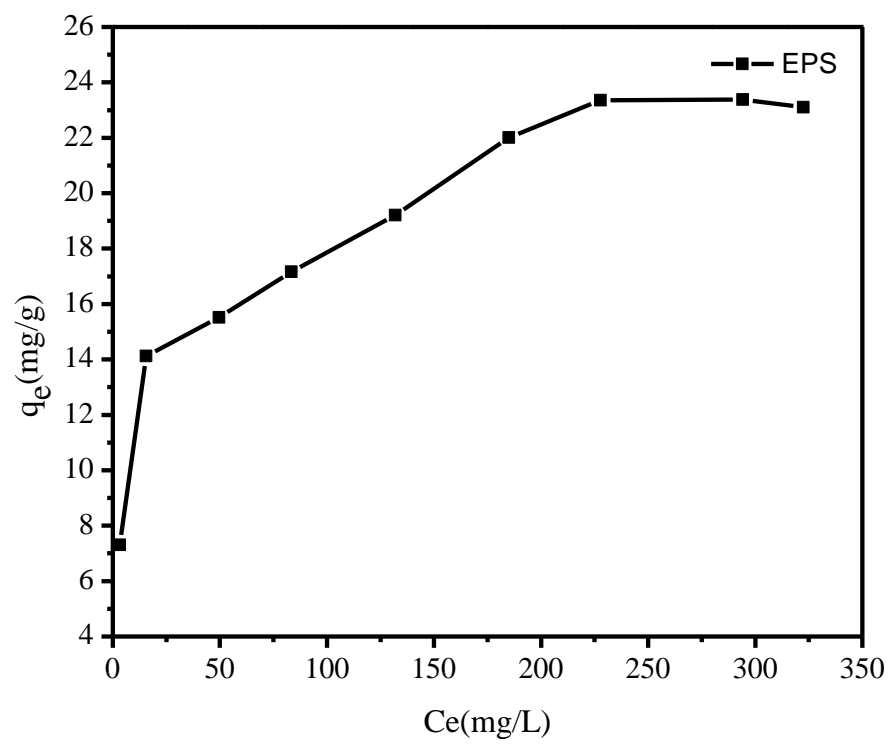

Fig.11 Effect of initial concentration of $\mathrm{Cr}$ (VI) on the adsorption by EPS.

To understand the adsorption type, Langmuir and Freundlich isotherm models were employed to simulate the experimental data. The Langmuir isotherm assumes the monolayer adsorption process on the surface of adsorbent ${ }^{[28]}$, while the Freundlich isotherm describes heterogeneous surfaces along with multi-layer adsorption processes. Langmuir isotherm model ${ }^{[29]}$ can be expressed as follows:

$$
\frac{C_{e}}{q_{e}}=\frac{C_{e}}{q_{\max }}+\frac{1}{q_{\max } K_{L}}
$$


Where $q_{e}$ and $C_{e}$ are the equilibrium adsorption capacity $(\mathrm{mg} / \mathrm{g})$ and equilibrium concentration $(\mathrm{mg} / \mathrm{L})$, respectively. $q_{\max }$ is the maximum adsorption capacity $(\mathrm{mg} / \mathrm{g})$, and $K_{L}$ is the Langmuir constant $(\mathrm{L} / \mathrm{mg})$.

Freundlich model ${ }^{[30]}$ can be expressed as follows:

$$
\log q_{e}=\log K_{f}+\frac{1}{n} \log C_{e}
$$

Where $q_{e}$ and $C_{e}$ are the equilibrium concentration $(\mathrm{mg} / \mathrm{L})$ and equilibrium adsorption capacity $(\mathrm{mg} / \mathrm{g})$, respectively. $K_{f}$ and $\mathrm{n}$ are the Freundlich constant. The Langmuir and Freundlich constants of the adsorption of $\mathrm{Cr}$ (VI) were calculated from the slopes and intercepts of the plots of $C e / q_{e}$ versus $C e$ (Fig.12a) and $\log q_{e}$ versus $C_{e}$ (Fig. 12b), which were summarized in Table 3.

As shown in Fig. 12 and Table. 3, The correlation coefficients $\left(\mathrm{R}^{2}\right)$ for both Langmuir and Freundlich isotherm models were larger than 0.94, suggesting that the $\mathrm{Cr}(\mathrm{VI})$ might be adsorbed on the surface of adsorbent in the mixed forms of monolayer and multilayer.

Table 3 Langmuir and Freundlich isothermal model parameters for the adsorption of Cr (VI) by EPS

\begin{tabular}{ccccccc}
\hline & \multicolumn{2}{c}{ Langmuir isothermal model } & \multicolumn{2}{c}{ Freundlich isothermal model } \\
\cline { 2 - 7 } Heavy & $\mathrm{b}(\mathrm{L} / \mathrm{mg})$ & $q_{\max }(\mathrm{mg} / \mathrm{g})$ & $R^{2}$ & $K_{f}(\mathrm{mg} / \mathrm{g})$ & $\mathrm{n}$ & $R^{2}$ \\
metals & & & & & & \\
\hline $\mathrm{Cr}(\mathrm{VI})$ & 0.04585 & 24.68 & 0.9905 & 6.100 & 4.177 & 0.9455 \\
\hline
\end{tabular}



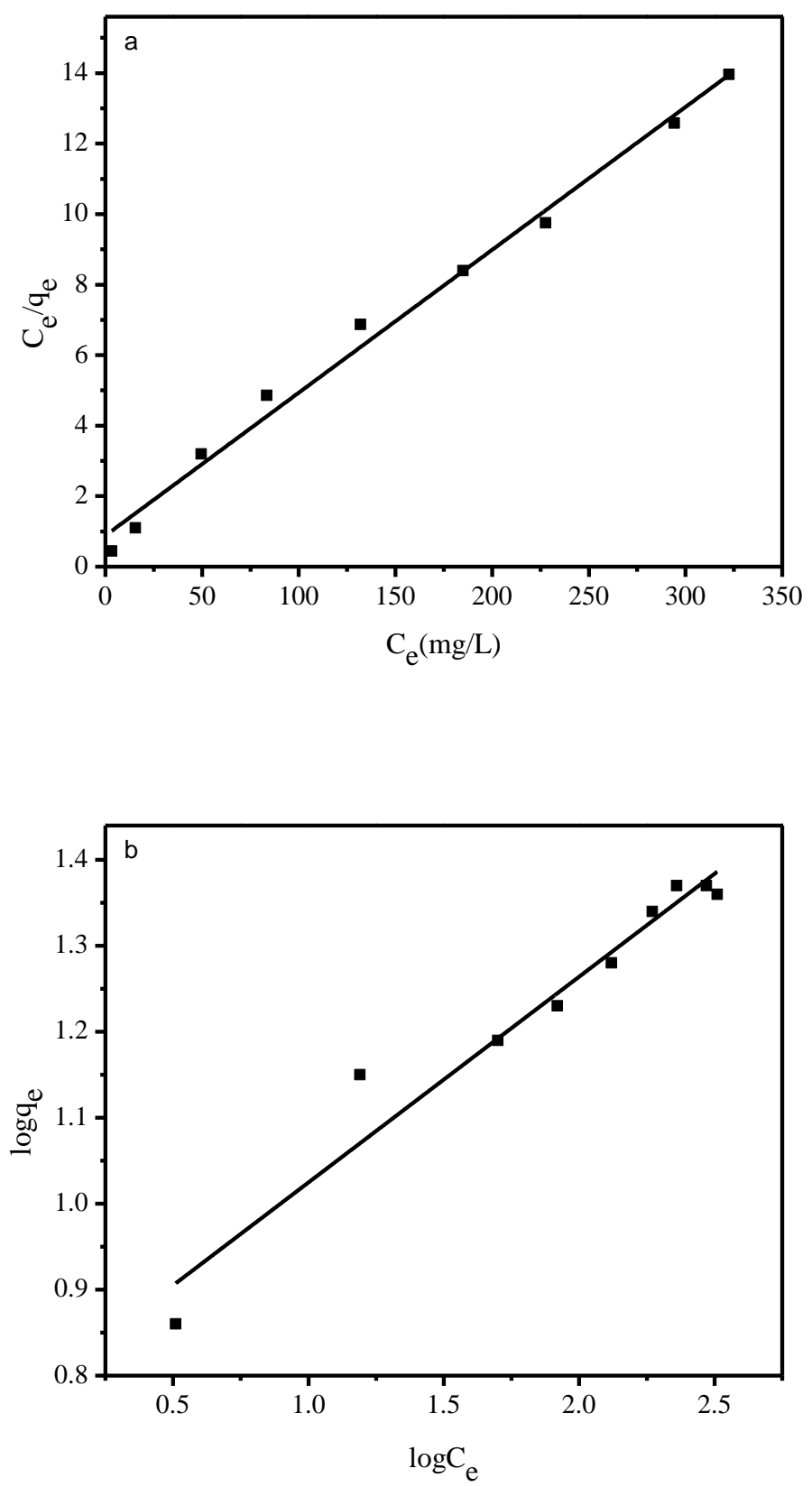

Fig.12 The models of adsorption (a) Langmuir isotherm model and (b) Freudlich isotherm model

In the present study, the maximum Cr (VI) uptake capacity was $24.68 \mathrm{mg} / \mathrm{g}$. Compared with the adsorbents developed by other researchers (Table 4), the adsorption capacities of $\mathrm{Cr}$ (VI) by EPS were similar or even higher than most of them. This result suggests that EPS is a promising adsorbent to treat effluent containing heavy metals.

Table 4 Comparison of $\mathrm{Cr}(\mathrm{VI})$ removal capacities by different adsorbents 


\begin{tabular}{ccc}
\hline Adsorbent & Adsorption capacity $(\mathrm{mg} / \mathrm{g})$ & Reference \\
\hline Rice straw & 3.15 & {$[33]$} \\
\hline Clarified sludge & 26.31 & {$[34]$} \\
\hline Natural Akadama clay & 4.29 & {$[35]$} \\
\hline Composite alginate - goethite beads & 29.5 & {$[36]$} \\
\hline Red mud & 21.1 & {$[38]$} \\
\hline Zeolites modified ZVI & 2.49 & This study \\
\hline EPS & 24.68 &
\end{tabular}

\subsection{Regeneration of EPS}

To use the adsorbent developed in this study repeatedly to further reduce the cost, it was very essential to investigate the regeneration ability of the adsorbents. As shown in Fig.13, it was observed that the adsorbents exhibited the good regeneration performance. The $\mathrm{Cr}(\mathrm{VI})$ adsorption capacity by EPS in the first regeneration cycle was $14.15 \mathrm{mg} / \mathrm{g}$ while it has a very slight decreased from 14.15 to $13.33 \mathrm{mg} / \mathrm{g}$ after four regeneration cycles. This result indicated that EPS is promising for $\mathrm{Cr}$ (VI) removal in the practical application with regeneration.

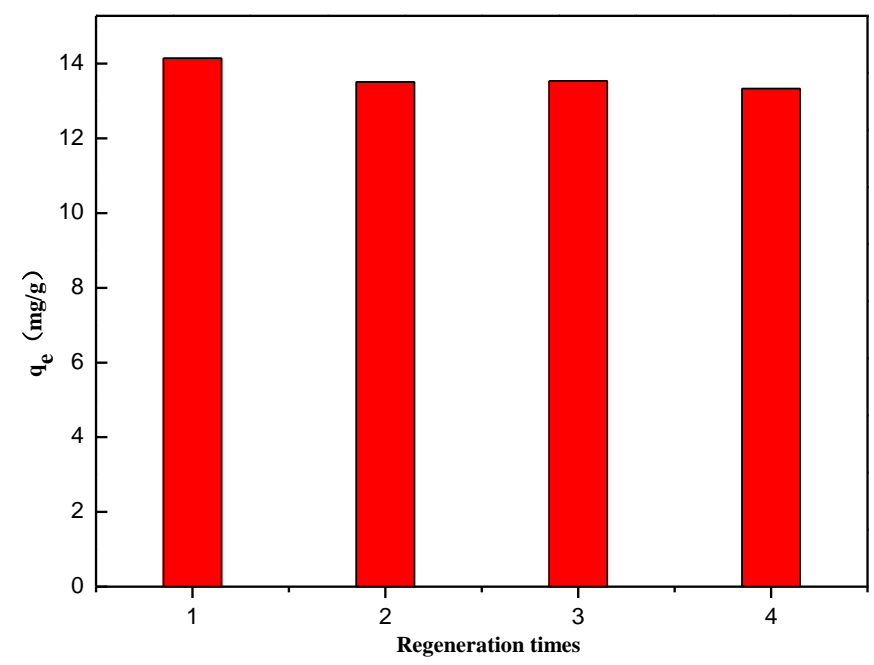

Fig.13 Regeneration study on the Cr (VI) removal by EPS 


\section{Conclusions}

EDA modified PS was developed as a new adsorbent to remove $\mathrm{Cr}$ (VI) from wastewater. FTIR, SEM, TGA and elemental analysis confirmed the presence of amino groups in PSafter modification. The pseudo-second-order kinetic model was well fitted with the adsorption data by EPS, implying that the adsorption process is controlled by chemisorption. For isotherm models, Langmuir adsorption model better described the adsorption of Cr (VI) by EPS than Freundlich model. The maximum adsorption capacity of $24.68 \mathrm{mg} / \mathrm{g}$ at $\mathrm{pH} 2.5$ by EPS suggested a comparable adsorption capacity compared with absorbents developed by other reseachers. Furthermore, EPS showed negligible adsorption capacity loss after 4 cycle of regeneration. All results from this study suggest that EPS is a promising and environmentally friendly absorbent by utilizing agricuture waste for the removal of $\mathrm{Cr}(\mathrm{VI})$ from wastewater.

\section{Acknowledgments}

This work was supported by Science and Technology Key R\&D Project "Integrated R\&D and Demonstration of Wastewater Treatment Stabilization Standards in Typical Industrial Clusters" of Sichuan Province (18ZDYF0051).

\section{References}

[1] Liu, Y., X. Sun and B. Li, Adsorption of $\mathrm{Hg}$ and Cd by ethylenediamine modified peanut shells. Carbohydrate Polymers, 2010. 81(2): p. 335-339.

[2] Raji, C. and T.S. Anirudhan, Batch Cr(VI) removal by polyacrylamide-grafted sawdust: Kinetics and thermodynamics. Water Research, 1998. 32(12): p. 3772-3780.

[3] Zhang R, Zhou Y, Gu X, et al. Competitive Adsorption of Methylene Blue and Cu2+ onto Citric Acid Modified Pine Sawdust[J]. CLEAN - Soil, Air, Water. 2015, 43(1): 96-103.

[4] Wang G, Wang S, Sun W, et al. Synthesis of a novel illite@carbon nanocomposite adsorbent for removal of Cr(VI) from wastewater[J]. Journal of Environmental Sciences. 2017, 57: 62-71.

[5] Altun T, Pehlivan E. Removal of $\mathrm{Cr}(\mathrm{VI})$ from aqueous solutions by modified walnut shells[J]. Food Chemistry. 2012, 132(2): 693-700. 
[6] Ghasemi M, Ghoreyshi A A, Younesi H, et al.(2015) Synthesis of a high characteristics activated carbon from walnut shell for the removal of $\mathrm{Cr}$ (VI) and Fe (II) from aqueous solution: single and binary solutes adsorption[Z]. 12.

[7] Sreenivas K M, Inarkar M B, Gokhale S V, et al. Re-utilization of ash gourd ( Benincasa hispida ) peel waste for chromium (VI) biosorption: Equilibrium and column studies[J]. Journal of Environmental Chemical Engineering. 2014, 2(1): 455-462.

[8] Wang X S, Qin Y. Removal of $\mathrm{Ni}(\mathrm{II}), \mathrm{Zn}(\mathrm{II})$ and $\mathrm{Cr}(\mathrm{VI})$ from aqueous solution by Alternanthera philoxeroides biomass[J]. Journal of Hazardous Materials. 2006, 138(3): 582-588.

[9] RSC Advances[J].

[10] Krishnani K K, Ayyappan S. Heavy metals remediation of water using plants and lignocellulosic agrowastes[J]. Rev Environ Contam Toxicol. 2006, 188: 59-84.

[11] Witekkrowiak A, Harikishore K R D. Removal of microelemental Cr(III) and Cu(II) by using soybean meal waste--unusual isotherms and insights of binding mechanism.[J]. Bioresource Technology. 2013, 127(127C): 350-357.

[12] Han R, Ding D, Xu Y, et al. Use of rice husk for the adsorption of congo red from aqueous solution in column mode.[J]. Bioresource Technology. 2008, 99(8): 2938-2946.

[13] Chowdhury S, Saha P D. Citric acid modified wheat bran as a potential adsorbent for removal of Cu(II) and Malachite Green from aqueous solutions[J]. Desalination \& Water Treatment. 2013, 51(31-33): 6038-6048.

[14] Altun T, Pehlivan E. Removal of Cr(VI) from aqueous solutions by modified walnut shells[J]. Food Chemistry. 2012, 132(2): 693-700.

[15] Mahmoud D K, Salleh M A M, Wan A W A K, et al. Batch adsorption of basic dye using acid treated kenaf fibre char: Equilibrium, kinetic and thermodynamic studies[J]. Chemical Engineering Journal. 2012, 181-182(2): 449-457.

[16] Pehlivan E, Altun T, Parlayici A. Modified barley straw as a potential biosorbent for removal of copper ions from aqueous solution[J]. Food Chemistry. 2012, 135(4): 2229-2234.

[17] Mwangi I W, Ngila J C. Removal of heavy metals from contaminated water using ethylenediaminemodified green seaweed ( Caulerpa serrulata )[J]. Physics \& Chemistry of the Earth. 2012, 50-52(2): 111-120.

[18] Kuppusamy S, Thavamani P, Megharaj M, et al. Oak (Quercus robur) Acorn Peel as a Low-Cost Adsorbent for Hexavalent Chromium Removal from Aquatic Ecosystems and Industrial Effluents[J]. Water, Air, \& Soil Pollution. 2016, 227(2).

[19] Yan J, Lan G, Qiu H, et al. Adsorption of heavy metals and methylene blue from aqueous solution with citric acid modified peach stone[J]. Separation Science \& Technology. 2018(10): 1-11.

[20] Wang Z, Han P, Jiao Y, et al. Adsorption of congo red using ethylenediamine modified wheat straw[J]. Desalination \& Water Treatment. 2011, 30(1-3): 195-206.

[21] Ma A, J L, Y S, et al. Adsorption mechanisms of removing heavy metals and dyes from aqueous solution using date pits solid adsorbent[J]. Journal of Hazardous Materials. 2010, 176(1): 510-520.

[22] 1967) Analytical letters[Z]. New York: M. Dekker.

[23] Yang H, Yan R, Chen H, et al. Characteristics of hemicellulose, cellulose and lignin pyrolysis[J]. Fuel. 2007, 86(12): 1781-1788.

[24] Rayón E, Ferrandiz S, Rico M I, et al. Microstructure, mechanical, and thermogravimetric characterization of cellulosic by-products obtained from biomass seeds.[J]. International Journal of Food Properties. 2015, 18(6): 1211-1222.

[25] Pehlivan E, Altun T. Biosorption of chromium(VI) ion from aqueous solutions using walnut, hazelnut and almond shell[J]. Journal of Hazardous Materials. 2008, 155(1): 378-384.

[26] Pitsari S, Tsoufakis E, Loizidou M. Enhanced lead adsorption by unbleached newspaper pulp modified with citric acid[J]. Chemical Engineering Journal. 2013, 223(3): 18-30.

[27] Fan H L, Li L, Zhou S F, et al. Continuous preparation of Fe 3 O 4 nanoparticles combined with surface modification by L -cysteine and their application in heavy metal adsorption[J]. Ceramics International. 2016, 42(3): 4228-4237.

[28] Sajab M S, Chia C H, Zakaria S, et al. Cationic and anionic modifications of oil palm empty fruit bunch fibers for the removal of dyes from aqueous solutions[J]. Bioresour Technol. 2013, 128(1): 571-577.

[29] Az B, As T, Py T, et al. Carboxymethyl- $\beta$-cyclodextrin conjugated magnetic nanoparticles as nanoadsorbents for removal of copper ions: synthesis and adsorption studies.[J]. Journal of Hazardous Materials. 2011, 185(2): 1177-1186.

[30] Chakravarty S, Pimple S, Chaturvedi H T, et al. Removal of copper from aqueous solution using newspaper pulp as an adsorbent[J]. Journal of Hazardous Materials. 2008, 159(2-3): 396-403.

[31] Gao, H., et al., Characterization of $\mathrm{Cr}(\mathrm{VI})$ removal from aqueous solutions by a surplus agricultural waste-rice straw. Journal of Hazardous Materials, 2008. 150(2): p. 446-452.

[32] Bhattacharya, A.K., et al., Adsorption, kinetics and equilibrium studies on removal of $\mathrm{Cr}(\mathrm{VI})$ from aqueous solutions using different low-cost adsorbents. Chemical Engineering Journal, 2008. 137(3): p. 529-541. 
[33] Zhao, Y., et al., Effective adsorption of Cr (VI) from aqueous solution using natural Akadama clay. Journal of Colloid \& Interface Science, 2013. 395(1): p. 198-204.

[34] Bajpai, J., R. Shrivastava and A.K. Bajpai, Dynamic and equilibrium studies on adsorption of Cr(VI) ions onto binary bio-polymeric beads of cross linked alginate and gelatin. Colloids \& Surfaces A Physicochemical \& Engineering Aspects, 2004. 236(1): p. 81-90.

[35] Gupta, V.K., M. Gupta and S. Sharma, Process development for the removal of lead and chromium from aqueous solutions using red mud--an aluminium industry waste. Water Research, 2001. 35(5): p. 1125-1134.

[36] Dang, H., Y. Zhang and P. Du, Enhanced removal of soluble Cr(VI) by using zero-valent iron composite supported by surfactant-modified zeolites. Water Science \& Technology, 2013. 70(8): p. 1398-1404 